\title{
EQUIPMENT FOR CALIBRATION IN-LINE APPLIANCES FOR TESTING PHYSICAL PARAMETERS OF WATER QUALITY
}

\author{
Dumitru Vlad ${ }^{1}$, Diana Mura Badea ${ }^{2}$, Daniela Bajenaru ${ }^{3}$ \\ 1,2,3 National Institute of Research and Development in Mechatronics and Measurement Technique \\ Bucharest, 6-8 Pantelimon Road, 2nd District, Romania \\ E-mails: didivlad2006@yahoo.com,dianammura@gmail.com,valibajenaru@yahoo.com
}

\begin{abstract}
In this paper we report on our experience in producing laboratory equipment (test stand) to determine the performance characteristics of on-line equipment for water analysis under controlled conditions. In this paper only reference is made to the physical parameters of drinking water. After building test bench facilities, an in-line sensor / equipment to determine performance characteristics using the comparison method should be considered. The performance characteristics to be determined are in accordance with the test procedures.
\end{abstract}

Keywords: Water Drinking Quality Parameters, Sensor Test.

\section{Introduction}

The quality conditions that drinking water must meet are rigorously established (regulated) by sanitary norms and standards. Sanitary norms are tables of a legal nature that include the limit values admitted for water quality indicators. [1]

Water quality standards are a set of rules defining the main quality characteristics that a water has to meet, the methods of analysis, the units of measurement, the terminology of the symbols used, etc. [2].

Each country has its own standards and water quality standards. However, worldwide it tends towards a common basis, resulting from the experience and needs of all. [3]. The common basis is represented by a reference system, accepted in most countries, which includes the limit values allowed for the physical, chemical and biological composition of water, which ensures the safe use of water for a particular destination.

In recent years the development of IT and communications technologies have a more significant contribution in the water processing management and the technologies for water quality control are undergoing continuous improvements. These technologies not only must comply with strict rules, safety measures, and quality standards, social and environmental challenges but also face serious problems of obsolete infrastructure, network leaks and the quality of drinking water. On the other hand, supplying clean drinking water and protecting the health of the population of the adverse effects of any contaminated water intended for human consumption are fundamental requirements of the European Directive 98/83/EC, transponded into
Romanian legislation law No. 458/2002 (amended and completed by law No. 311/2004 and the Governmental Ordinance No. 11/2011).

As a result, there is a market demand for drinking water management solutions considering that current technologies are far from satisfying the legal requirements in terms of monitoring, remote transmission and data processing for water quality. To know the water quality monitoring solution currently used is manual removal of samples, in certain specific points (especially the plug) transport to laboratory, measurements and issuing a report.

\section{The current situation in the country}

Drinking water quality monitoring can be achieved only in laboratories registered with the Ministry of Health. Registration is a process of recognition of the drinking water is done within the laboratories of DSP [4].

The manufacturers water quality monitoring is based on rigorous technical procedures and advanced control tools. Water monitoring is carried out in water plants (automated analyzers track each phase of water treatment to verify its effectiveness), in water tanks and on the distribution network, all these being coupled with laboratory analysis.

Annually about 120.000 indicators are analyzed on over 6.000 samples collected from the distribution network [5].

To know the water quality monitoring solution currently used is manual removal of samples, in certain specific points (especially the plug), transport to laboratory, measurements and issuing a report. 
Sampling is currently in a period of time and the test results are known after $7 \div 10$ days from the date of sampling. In this way, exceeding the maximum permissible content of chemical elements or physical, is known only after the event, without being able to take swift action.

These laboratories equipment is not used in the field (expeditionary) and is not adaptable monitoring system water transport buses [6].

\section{The current situation abroad}

To highlight existing solutions on the market must mention two technical solutions for measuring parameters of drinking water. In-line measurement is made by placing measurement probes inside the pipes, and the on-line measurement of water sample is pumped from the water pipe to additional analytical tools pipeline. Currently for measuring online there are a variety of multi parameter probes used to determine several physic parameters such as: pressure, temperature, $\mathrm{pH}$, turbidity, residual chlorine, total organic carbon (TOC), and turbidity [7].

\section{General description of the product}

Constructively, the adopted scheme of equipment for in-line calibration of apparatuses for determining the physical parameters of water quality is shown further (Fig.1).

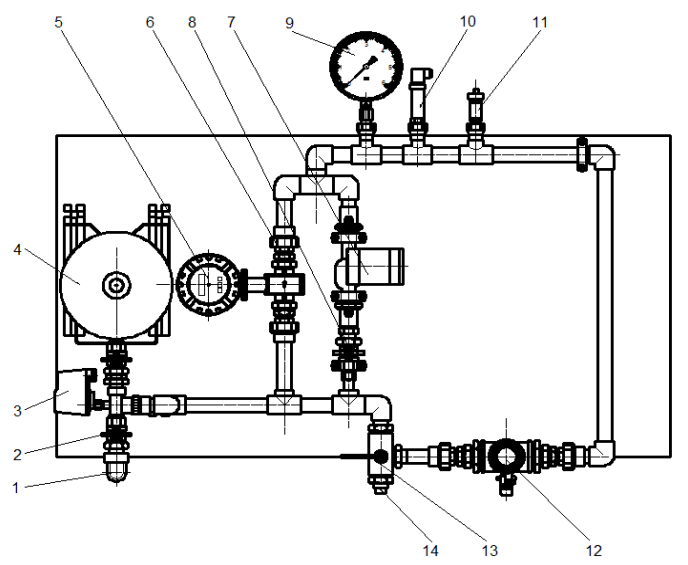

Figure 1: General description

The equipment consists of the following components: water reservoir, 1 -sumersible pump, 2 -valve A, 3- pressure switch, 4- hydropneumatic accumulators in which the fluids are separated by balloon, 5 -electromagnetic flowmeter, 6- sense valve, 7 - recirculating pump, 8 - valve B, 9 -pressure indicator, 10 - pressure and temperature transducer, 11 - ventilation valve, 12 - a bypass where the measuring probes and the monitoring system are mounted, 13 - 3-way pass valve, 14 - emptying path, pipes and fittings, elbows, mass support, etc.
Operation:

After mounting the calibrator in the by-pass where the measuring probes and the monitoring system are mounted, depending on the parameters determined, the stand provides two modes of operation:

\section{A Closed system operation;}

A pressure of 1.5 bar is provided in the hydropneumatic accumulator. With valve 2 in open position, valve 9 in open position and three-way valve having outlet path 14 closed, the water in the tank is pumped into the pipes at a pressure set by means of the pressure switch 3 . At the moment of reaching the desired working pressure, the pump is disconnected by means of the pressure switch and closing valve 2 . Air in the system is drained through the air valve. Start the water recirculation pump on the system at the flow rate it provides. We have the choice of three flow rates. The pressure and temperature transducer 10 together with the flow meter 5 provides information on each measured parameter by displaying the measured values on the control and control panel (laptop). The water passes through the bypass on which the calibrating apparatus is mounted and further returns to the tank by opening the three-way valve through the discharge head 14 after the calibration.

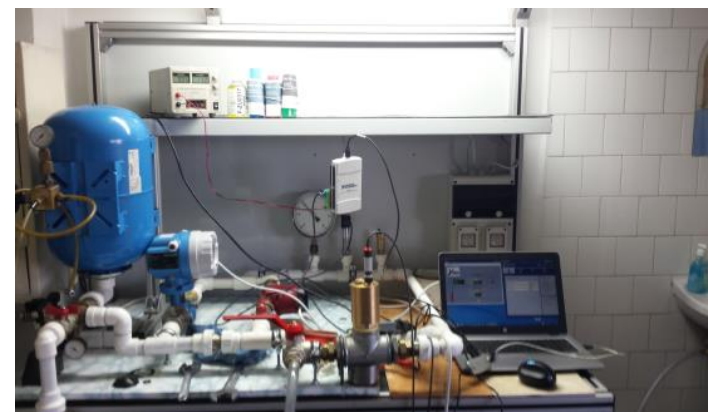

Figure 2: Specialized equipment for calibration in-line

\section{B.Open system operation;}

A pressure of 1.5 bar is provided in the hydropneumatic accumulator. With valve 2 in open position, tap 9 in the closed position and three-way valve having outlet path 14 open, tank water is pumped into the pipes at a pressure and flow comparable to those encountered in the water supply network. The air in the system is drained through the air vent valve. The pressure and temperature transducer 10 together with the flow meter 5 provides information on each measured parameter by displaying the measured values on the control and control panel (laptop). The water passes through the bypass on which the calibration device is mounted, and then returns to the tank through the throttle tap 14 of the tap. The calibration of the appliance is carried out with the pump in operation. 
Determining performance characteristics of sensors for analyzing the physical parameters of water in the laboratory, under controlled conditions, it can be described using the diagram as shown in Figure 3. [8]

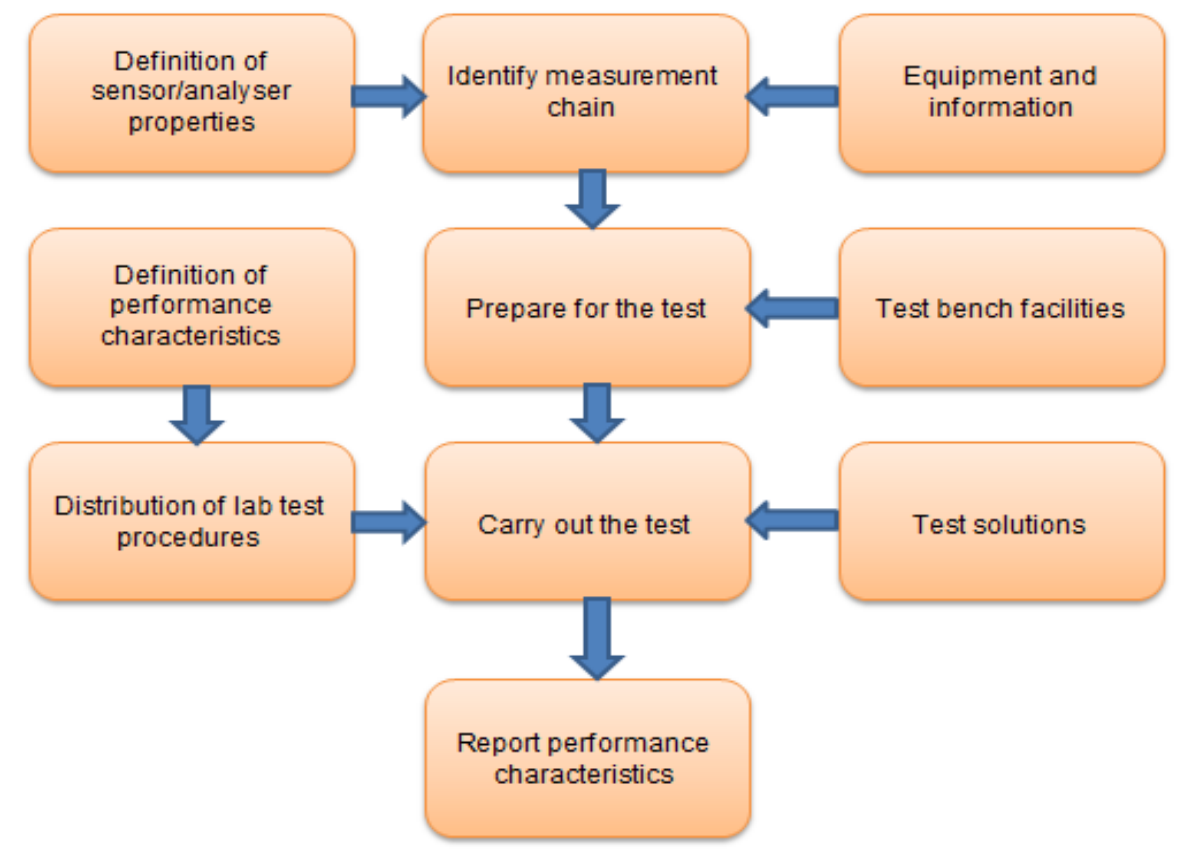

Figure 3: Overview of test

\section{Sizing calculation}

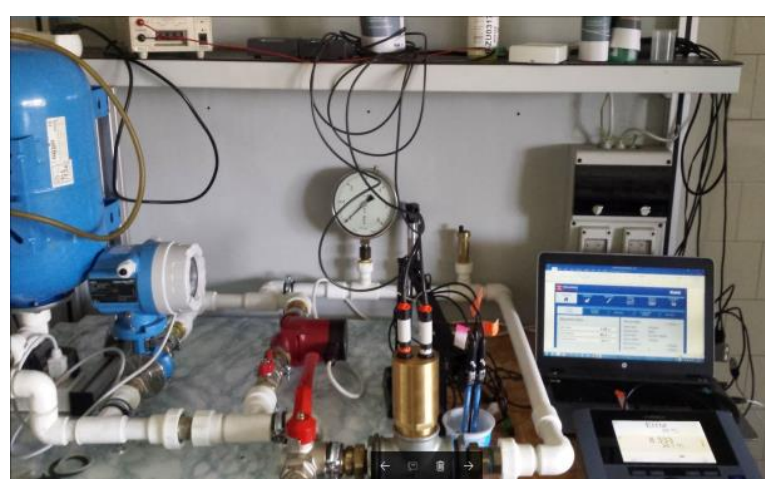

Figure 4: Calibration test

The sizing calculation of the water supply pipe of the stand was made.

\section{(a) Determining the diameter}

Formula:

$$
d_{0}=\sqrt{\frac{4 \cdot q_{x}}{2 \cdot 14 w_{x}}}
$$

where

- $\mathrm{v}_{\mathrm{a}}=1 \ldots .3 \mathrm{~m} / \mathrm{s}$, water flow through the pipe;

- $\mathrm{q}_{\mathrm{a}}=3.5 \mathrm{~m} 3 /$ hour $=0.0009722 \mathrm{~m} 3 / \mathrm{s}$, the flow rate of water required for feeding.

We choose $v_{a}=3 \mathrm{~m} / \mathrm{s}$ and result is:

$$
\mathrm{d}_{0}=\sqrt[2]{\frac{4 * 0.000972}{3.14 \times a}}=0.020 \mathrm{~m}=20 \mathrm{~mm}
$$

\section{(b) Choosing pipework}

Pipes are made of Polypropylene Random PPR type 3 (MRS = $8 \mathrm{~N} / \mathrm{mm} 2$ ) according to SR EN ISO 15874 .

- The nominal diameter, $\mathrm{d}$ refers to the outer diameter in mm;

- Nominal thickness, s in mm;

- Standard Dimension Ratio: SDR = d / s;

- Series S: S = (SDR-1) / 2;

- MRS=required minimum resistance (circumferential stress) expressed in MPa: MRS = 8.0 Mpa.

Choose PPR Ø 32x4,4, SINIF 1/10 bar, SDR 7,4.

\section{(c) Determination of actual flow velocity}

Formula:

$$
v=\frac{4 * q_{a}}{\pi * d^{2}}
$$

where:

$\mathrm{v}=$ actual flow velocity $(\mathrm{m} / \mathrm{s})$;

$\mathrm{q}_{\mathrm{a}}=$ flow $(\mathrm{m} 3 / \mathrm{s}) ;=0.000972$

$\mathrm{d}=$ pipeline diameter $=23.2 \mathrm{~mm}=0.023 \mathrm{~m}$

$\mathrm{v}=(4 * 0.000972) /\left(3.14 *[0.023]^{\wedge} 2\right)=2.34 \mathrm{~m} / \mathrm{s}$

$$
v=\frac{4 \cdot 0.000972}{a .14 \cdot 0.02 \mathrm{a}^{2}}=2.34 \mathrm{~m} / \mathrm{s}
$$

\section{(d) Determination of Reynolds number

$$
\mathrm{R}_{\mathrm{e}}=\frac{\mathrm{w}_{\mathrm{d}}}{\mathrm{n}_{\mathrm{a}}}
$$

Where: $\mathrm{n}_{\mathrm{a}}=1.52 * 10-6 \mathrm{~m} 2 / \mathrm{s}$ is the kinematic viscosity of the water 


$$
\mathrm{R}_{\mathrm{e}}=\frac{2 . \mathrm{a4} * 0.023}{1.52 \cdot 10^{-6}}=35.407
$$

\section{(e) Determining the hydraulic resistance factor}

\section{Formula:}

for the laminar regime,

$$
\mathrm{Re}_{\mathrm{e}}<2300: \lambda=\frac{64}{\mathrm{R}_{\mathbf{e}}}
$$

for the turbulent regime,

$$
\mathrm{R}_{\mathrm{e}}>2300: \lambda=\frac{0.3164}{\mathrm{R}_{\mathbf{2}}{ }^{10.25}}
$$

Because $R_{e}>2300$, it results

$$
\lambda=\frac{0.3164}{35407^{0,25}}=0.023
$$

\section{(f) Determination of pressure drop}

Formula:

$$
\Delta p=\lambda \frac{L_{a}}{d} p_{a} \frac{w^{2}}{2}+p_{a} g\left(z_{1}-z_{S A}\right)
$$

Where:

- $\mathrm{l}=0.01745$, the hydraulic resistance coefficient,

- $\mathrm{r}_{\mathrm{a}}=1.000 \mathrm{~kg} / \mathrm{m} 3$, water density,

- At $=3 \mathrm{~m}$, pipe length,

- $\mathrm{z}_{1}=0 \mathrm{~m}$, the share of the initial pipeline point,

- $\mathrm{ZSA}_{\mathrm{SA}}=0 \mathrm{~m}$, share of the end point of the pipeline.

Result:

$\Delta p=\frac{0.3164}{35407^{0,25}} * \frac{a}{0.02 a} * 1000 * \frac{2.34^{2}}{2}=8213.4 \mathrm{~Pa}$

The main technical characteristics of the specialized equipment for in-line calibration of the apparatuses for determining the physical parameters of the water quality are the following:

- Work environment: fluid (water);

- Pressure: minimum 0,7 bar and maximum 6 bar

- Working pressure: max. 3 bar

- Flow rate: $\mathrm{F}_{\min }=0.1887 \mathrm{mc} / \mathrm{s} ; \mathrm{F}_{\max }=0.55 \mathrm{mc}$ $/ \mathrm{s} ; \mathrm{F}_{\text {work }}=0.25 \mathrm{mc} / \mathrm{s}$

- Temperature: $25 \pm 5{ }^{\circ} \mathrm{C}$

- Power supply: 50Hz; 1x230 V; 0 ... 24 VDC

- Pump: $0.016 \mathrm{mc} / \mathrm{s}-0.09 \mathrm{mc} / \mathrm{s}$

- Tank: 801

\section{Conclusions}

The experimental researches validated the constructive solutions chosen for the calibration stand in the field of physical parameters measurement of water quality, dynamic behavior of sensors, as well as the proposed test method for determining the main parameters influencing this behavior.

There are four series of measurements, three series with closed system operation and 1 series, in open system.

The experimental research on the behavior of the specialized equipment for the in-line calibration of the apparatuses for the determination of the physical parameters of the water quality, allowed the determination of the functional parameters, as well as the recording of the evolution of the physical parameters according to the variation of the pressure and the flow rate.

\section{References}

[1] Law No.458 of the Romanian Parliament of 8 July 2002 on drinking water quality;

[2] STAS 1342/91- Apă potabilă

[3] Current Online Water Quality Monitoring Methods and Their Suitability for the Western Corridor Purified Recycled Water Scheme - Roger O'Halloran, Shoshana Fogelman, and Huijun Zhao, October 2009;

[4] Department of Public Health;

[5] http://www.apanovabucuresti.ro/infoconsumator

[6] EU-WFD 2003. Common implementation strategy for the Water Frame Work Directive (2000/60/EC),Guidance Document No. 7. Monitoring under theWater Framework Directive Produced by WorkingGroup 2.7 - Monitoring (2003);

[7] FP7 - 217976/SecurEau - Security and decontamination of drinking water distribution systems following a deliberate contamination;

[8] ISO 15839:2003 - Water quality-On-line sensors/analyzing equipment for waterSpecification and performance tests. 